\title{
On Carcinoma of the Gallbladder with Special Reference to the Relation with Calculous or Inflammatory Diseases
}

By

\author{
Masao Muto, Susumu Majima and Hiroshi Otsuki \\ （武藤 完 雄）（間 島 進） (大 柣弘) \\ Prof. M. Muto's Surgical Clinic, Tohoku University, Sendai
}

(Received for publication, August 29, 1959)

It is well known that the carcinoma of the gallbladder is not unusually accompanied with calculi. In fact, we often observed such a concurrence.

Besides, we also experienced some cases which had been cholecystectomized for calculous diseases and in which the gross or, in some instances, the microscopic studies of the open gallbladder revealed the co-existence of carcinoma.

These facts suggest some relations between carcinoma of the gallbladder on one hand and calculous or inflammatory diseases of the same organ on the other hand. To clarify this problem, thorough examinations were carried out in 263 gallbladders which had been extirpated for various surgical disorders.

\section{Experimental AND Comments}

\section{Objects}

The objects of this study were 263 gallbladders ectomized in our clinic during the last 17 years for various cholecystic disorders, items of which are shown in Table I.

\section{Carcinoma Cases}

Among 24 carcinoma cases, tumors could be recognized during operation in 17 cases, while in the remaining seven, examinations of the gallbladder ectomized for calculous or inflammatory diseases found first the concurrence of carcinomatous lesions.

Twenty four carcinomas of the gallbladders are classified by their gross forms, according to Hanser, ${ }^{11}$ as shown in Table II. These comprised three cases of the pedunculated papillary type (Fig. 1), three cases of the broad-based papillary type (Fig. 2), five of the nodular type (Fig. 3) and 13 of the diffusely infiltrating type (Figs. 4 and 5). 
TABLE I

Items of Cholecystic Disorders Operated in Our Clinic

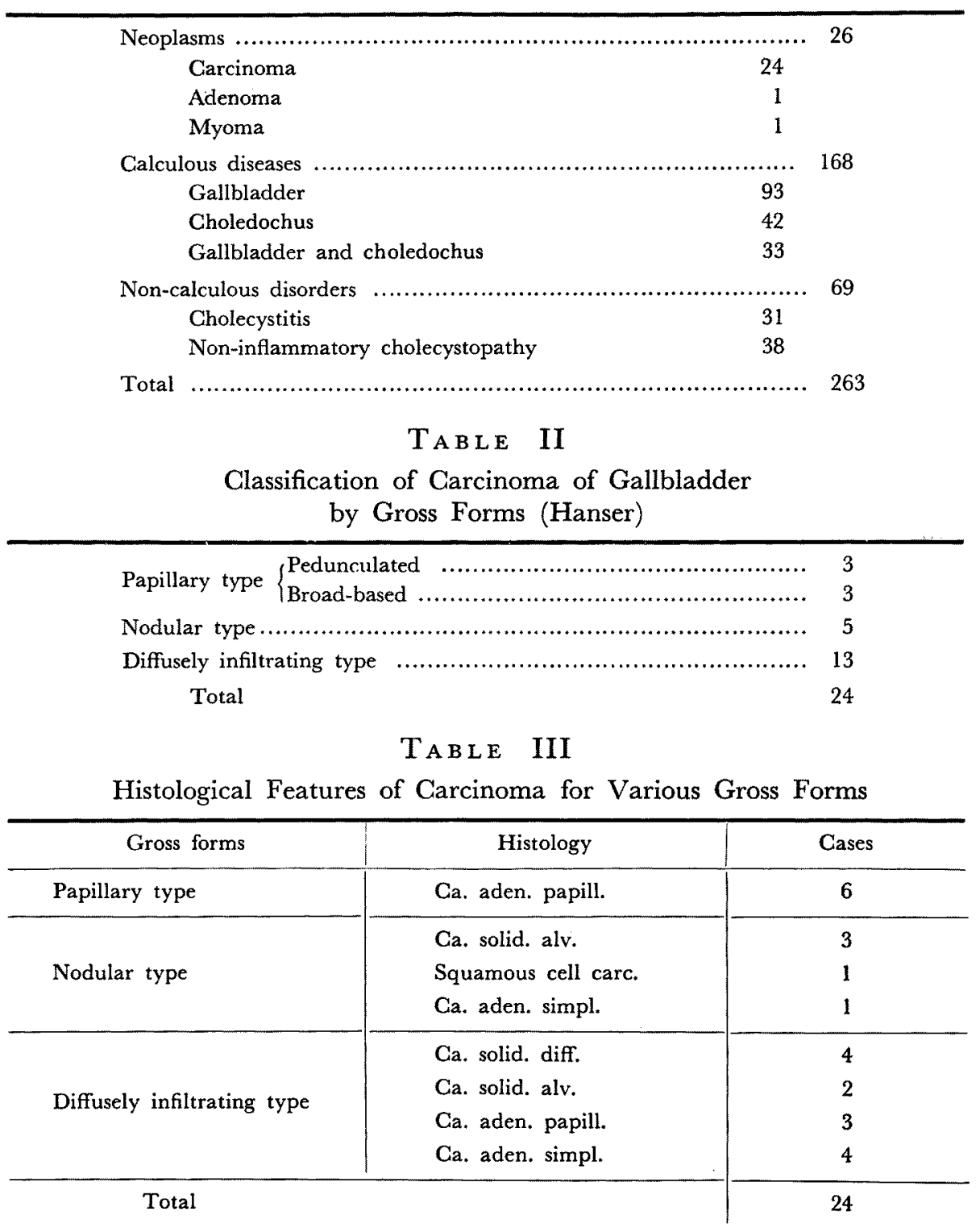

In Table III are given the microscopic diagnoses of the main tumors of these cases, for each one of their gross forms. As to the characteristic features in their histology, refer to Figs. 6, 7, 8 and 9.

The rate of the lymph-nodal involvement, meatstasis to the liver or 
TABLE IV

Spread of Lesion in Carcinoma of Gallbladder

\begin{tabular}{l|c|c|c}
\hline & \multicolumn{3}{|c}{ No. of cases with* } \\
\cline { 2 - 4 } & $\begin{array}{c}\text { Lymph-nodal } \\
\text { involvement }\end{array}$ & $\begin{array}{c}\text { Metastasis to } \\
\text { the liver }\end{array}$ & $\begin{array}{c}\text { Infiltration to the } \\
\text { serous membrane }\end{array}$ \\
\hline Papillary type & $2 / 6$ & $2 / 6$ & $0 / 6$ \\
Nodular type & $5 / 5$ & $3 / 5$ & $2 / 5$ \\
Diffusely infiltrating type & $12 / 13$ & $4 / 13$ & $13 / 13$ \\
\multicolumn{2}{c}{ * Denominators show the total numbers. }
\end{tabular}

the invasion to the serous membrane in these cases is shown in Table IV, there being found a comparatively high occurrence of the incipient figures of malignant spreads, already at the time of operation.

Early carcinoma lesions found in the carcinomatous gallbladders

Two of the above-mentioned 24 cases showed the figures of early carcinoma originated in pre-existed papillomas, and eight had the accessory, early malignant lesions beside the main tumors, ranging from one to three in number. The location of the lesions in these ten cases with early carcinomas is outlined in Fig. 10.

In Case 1, two papillomas were found, being about the size of a finger tip and of a pigeon's egg, respectively. Microscopically, both of them presented the characteristic features of papilloma being composed of the network of the coralliform stroma and of a layer of the high-columnar epithelium covering it. And in the latter, a lesion of carcinoma in situ was discovered (Fig. 11).

Though Case 2 was an aggravated papilloma showing almost similar histology to Case 1, the carcinoma in situ in this case showed, in part, the infiltration (Fig. 12).

In the above two cases, besides, papillary proliferations of the epithelium were recognized even at the outside of the mentioned main lesions, which were thought to be incipient figures of papilloma. Especially in Case 2, such a proliferated epithelium showed, in part, an apparent evidence of atypicality and was considered to be a precancerous lesion. Recently, similar cases viz. papillomas of the gallbladder accompanied with carcinomatous aggravations were reported also by other authors, for example, a case by Nagai' ${ }^{2)}$ and Miyaji, ${ }^{32}$ respectively, and three cases by Tabah.4)

In the other eight cases, Cases 3 to 10 , one to three foci of early carcinoma were observed microscopically beside the main tumor (two cases of the broad-based papillary type, three of the nodular type and three of the infiltrating type), as stated above. 
Gallbladder walls of Cases 3 to 9, the majority of these cases, presented the figures of severe chronic inflammation, these mucous membranes being rather atrophic in general. And in the latter, there were found scattered foci of papillary or adenomatous growths of the epithelium, a part of which showed the obvious atypicalities such as variations in size of the epithelial cells, polymorphies, enlargement of the nuclei or disappearance of the polarity.

In some instances, such papillary or adenomatous growths with the atypical structure showed marked irregularities, invading the stroma with the irregular nests or cords of the proliferated cells, initial figures of the infiltrating growth were thus observed (Fig. 13).

In Case 10, the mucous membrane of which was hypertrophic and a focus of carcinoma in situ was observed therein, infiltration into the stroma was not yet observed (Fig. 14).

In the above-mentioned eight cases, Cases 3 to 10, histological studies of the serial sections failed to detect the patho-histological continuity between the main tumor and any one of the accessory early malignant lesions. Moreover, the main tumor of Case 6 was squamous cell carcinoma, while the early carcinoma lesions of the same case were adenocarcinoma composed of the high-columnar cells.

These interesting findings suggest that the carcinomatous foci of the gallbladder mucosa in such cases had possibly been initiated " multicentrically". Already Willis" noticed that the early carcinomas of the gallbladder were not unusually of the multicentric or the wide-spread and progressive origin.

III. Epithelial Overgrowths in Calculous or Inflammatory Gallbladder

It is a fact of a clinical evidence that the carcinoma of the gallbladder is often accompanied with calculi, the reported rate of the concurrence being as shown in Table V. As to our cases, 15 (62.5 per cent) of 24 carcinomas of the gallbladder were complicated with cholecystolithiasis. The number of the calculi in our cases was one to nine in eight cases and ten or more in the other cases, the largest one being 46 .

Such a not unusual concurrence of the carcinoma and the calculi may suggest the pathogenetic relation between them. Therefore we performed thorough examinations of the 237 gallbladders ectomized for various cholecystic disorders other than neoplasms, especially intending to discover the papillary or adenomatous proliferations or the precancerous gorwths.

Relation with the calculi

Among the mentioned 237 cases, 168 were calculous and 69 were non-calculous. The results are summarized in Table VI. 
TABLE V

Rate of Concurrence of Calculi in

Carcinomatous Gallbladder

\begin{tabular}{l|c|r}
\hline \multicolumn{1}{c|}{ Authors } & Total cases & Concurrent cases \\
\hline Judd & 56 & $53(94.4 \%)$ \\
Russel & 22 & $19(86.4 \%)$ \\
Johnes & 50 & $41(82.0 \%)$ \\
Courvoisier & 84 & $74(76.2 \%)$ \\
Arminski & 2068 & $1514(73.2 \%)$ \\
Smithies & 23 & $16(69.6 \%)$ \\
Ourselves & 24 & $15(62.5 \%)$
\end{tabular}

TABLE VI

Rate of Occurrence of Anomalously Proliferated Epithelium in Calculous and in Non-calculous Gallbladders

\begin{tabular}{l|c|c|c}
\hline & $\begin{array}{c}\text { Total } \\
\text { cases }\end{array}$ & $\begin{array}{c}\text { Papillary or adenomatous } \\
\text { proliferation }\end{array}$ & $\begin{array}{c}\text { Precancerous } \\
\text { growth }\end{array}$ \\
\hline Calculous & 168 & $25(14.6 \%)$ & $7(4,1 \%)$ \\
Non-calculous & 69 & $6(8.7 \%)$ & $1(1.4 \%)$ \\
\hline \multicolumn{1}{c|}{ Total } & 237 & $31(13.1 \%)$ & $8(3.3 \%)$
\end{tabular}

In 25 (14.6 per cent) of the 168 calculous cases anomalous proliferations of the epithelium, either papillary or adenomatous, were observed, seven (4.1 per cent) of which were revealed to be precancerous. Among the 69 cases with non-calculous disorders, on the other hand, such epithelial overgrowths were found in six cases (8.7 per cent), precancerous growth being observed in only one of them.

Relation with the inflammation

All of the mentioned 237 gallbladders were complicated with inflammations, whether acute or chronic and whether marked or mild. These were then studied for the relation with the anomalous proliferation of the epithelium.

Then, all of the 13 cases with marked acute inflammation showed no sign of the epithelial overgrowth, whereas many of the cases with chronic inflammations were accompanied with the evident anomalous proliferations of the epithelium (Table VII). Thus, among the 131 cases with mild chronic inflammations, whether with or without acute inflammation, six (4.6 per cent) showed the epithelial overgrowth, one ( 0.7 per cent) of which was thought to be a precancerous lesion; and among the 93 cases with marked chronic inflammation, also with or without acute 
pictures, such overgrowths were found in 25 cases (26.9 per cent), seven (7.5 per cent) out of them being obviously precancerous.

From these results it was revealed that the anomalous proliferations of the epithelium of the gallbladder are most common in cases with marked chronic inflammation.

\section{TABLE VII}

Rate of Occurrence of Anomalously Proliferated Epithelium for Each Sort of Inflammations

\begin{tabular}{c|c|c|c}
\hline & $\begin{array}{c}\text { Total } \\
\text { cases }\end{array}$ & $\begin{array}{c}\text { Papillary or adeno- } \\
\text { matous proliferation }\end{array}$ & $\begin{array}{c}\text { Precancerous } \\
\text { growth }\end{array}$ \\
\hline Acute inflammation & 13 & $0(0.0 \%)$ & $0(0.0 \%)$ \\
Chronic inflammation $\left\{\begin{array}{l}\text { Mild } \\
\text { Marked }\end{array}\right.$ & 131 & $6(4.6 \%)$ & $1(0.7 \%)$ \\
\hline Total & 93 & $25(26.9 \%)$ & $7(7.5 \%)$ \\
\hline & 237 & $31(13.1 \%)$ & $8(3.3 \%)$
\end{tabular}

Relation with the lapse of time since onset of the disease

Next, the rate of occurrence of the epithelial overgrowths was studied according to the lapse of time from the onset of the disease, which was presumed from the history of patient, to the operation.

As seen in Table VIII, the rate of the occurrence of the anomalous epithelial proliferation was 9.5 per cent in 147 cases which had been operated within five years from the onset of the disease, while that of

\section{TABLE VIII}

Relation between Epithelial Proliferation and Lapse of Time since Onset of Cholecystic Disorders

\begin{tabular}{c|c|c|c}
\hline $\begin{array}{c}\text { Lapse of time } \\
\text { (years) }\end{array}$ & $\begin{array}{c}\text { Total } \\
\text { cases }\end{array}$ & $\begin{array}{c}\text { Papillary or adenomatous } \\
\text { proliferation }\end{array}$ & Precancerous growth \\
\hline $0-1$ & 86 & $9(10.5 \%)$ & $1(1.2 \%)$ \\
$2-4$ & 61 & $5(8.2 \%)$ & $2(3.3 \%)$ \\
Total & 147 & $14(9.5 \%)$ & $3(2.0 \%)$ \\
\hline $5-11$ & 59 & $13(22.1 \%)$ & $4(6.8 \%)$ \\
$11-44$ & 31 & $4(12.9 \%)$ & $1(3.2 \%)$ \\
Total & 90 & $17(18.9 \%)$ & $5(5.6 \%)$ \\
\hline Total & 237 & $31(13.1 \%)$ & $8(3.3 \%)$ \\
\hline
\end{tabular}

the 90 cases operated five years or more after the onset was as high as 18.9 per cent.

To conclude, from the histological examinations of the 237 gall- 
bladders which were ectomized for surgical disorders other than neoplasms, the anomalous proliferations of the epithelium were discovered in 31 (13.1 per cent) of them. Though such epithelial overgrowths were more common in calculous cases than in non-calculous ones, these were revealed to be correlated much more closely with the presence of the inflammations, being observed in highest rate in the cases with marked chronic cholecystitis.

\section{SUMmary}

1. Twenty four cases with carcinoma of the gallbladder were studied histologically. In ten gallbladders, one to three early microscopic lesions of carcinoma were observed beside the main tumors, suggesting that the multicentric occurrence of the lesion is not unusual.

2. Among the above 24 cases, 15 (62.5 per cent) were complicated with calculi. Such a high rate of the concurrence suggested some relations between the two conditions, therefore thorough microscopic studies were performed on 237 gallbladders which had been ectomized for various surgical disorders other than neoplasms.

3. The papillary or adenomatous proliferations of the epithelium were observed in 31 ( 13.1 per cent) of the 237 cases, i.e. in 25 (14.6 per cent) of the 168 calculous and in six (8.7 per cent) of the 69 non-calculous cases, among which eight cases were evidently precancerous.

These epithelial overgrowths were, however, more closcly dependent upon the existence of the infiammations than the presence of calculi, and these were observed most commonly in cases with the marked chronic inflammations.

\section{References}

1) Hanser, Henke-Lubarsch's Handb. d. spez. path. Anat. u. Hist, 1929, Berlin, Bd. V, T. 2,748 .

2) Nagai, J. Jap. Surg. Soc. (Jap.), 1950, 55, 1183.

3) Miyaji, ibid., 1952, 58, 704.

4) Tabah, Surgery, 1933, 34, 57

5) Willis, Pathology of Tumors, 1953, London, p. 438. 


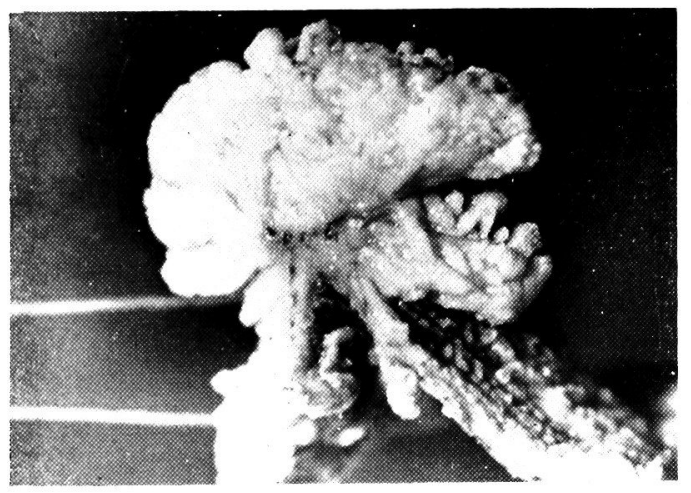

Fig. 1. Carcinoma of the gallbladder.

Pedunculated papillary type, which was revealed histologically to be an early carcinoma and to have occurred in a pre-existed papilloma.

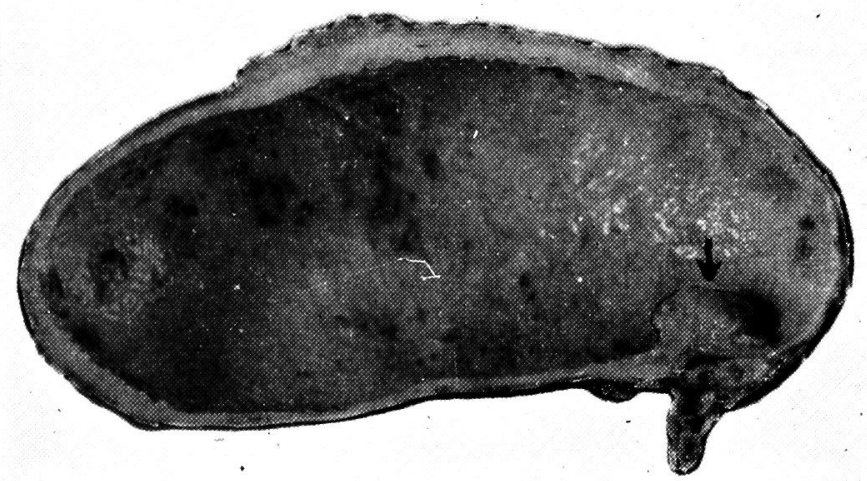

Fig. 2. Carcinoma of the gallbladder.

Broad-based papillary type (shown by an arrow) originated in the neck of the gallbladder.

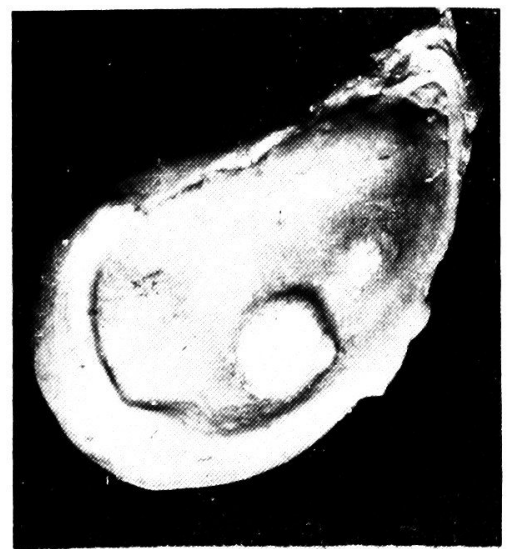

Fig. 3. Carcinoma of the gallbladder. Two tumors of the nodular type. 
Fig. 4

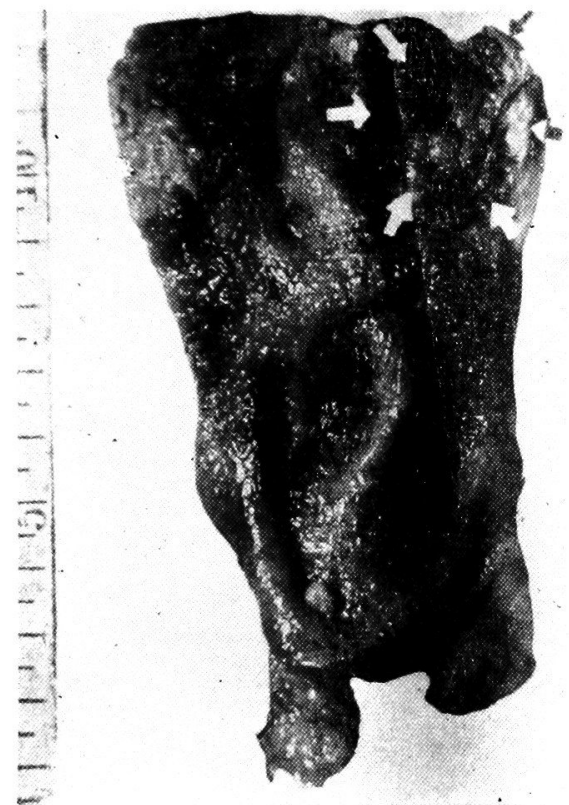

Fig. 5
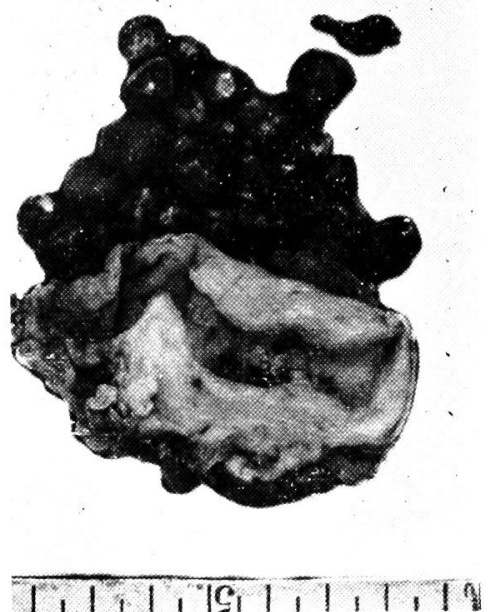

Fig. 4. Carcinoma of the gallbladder.

Diffusely infiltrating type. In this case, the lesion (shown by arrows) is limited to only a portion of the gallbladder.

Fig. 5. Carcinoma of the gallbladder.

Diffi:sely infiltrating type. Almost all areas of the mucous membrane are involved. Notice the extreme constriction of the gallbladder. Outside of the bladder are shown the co-existed calculi.

Fig. 6. Carcinoma adenomatosum papilliferum, constructed of high-columnar cells.

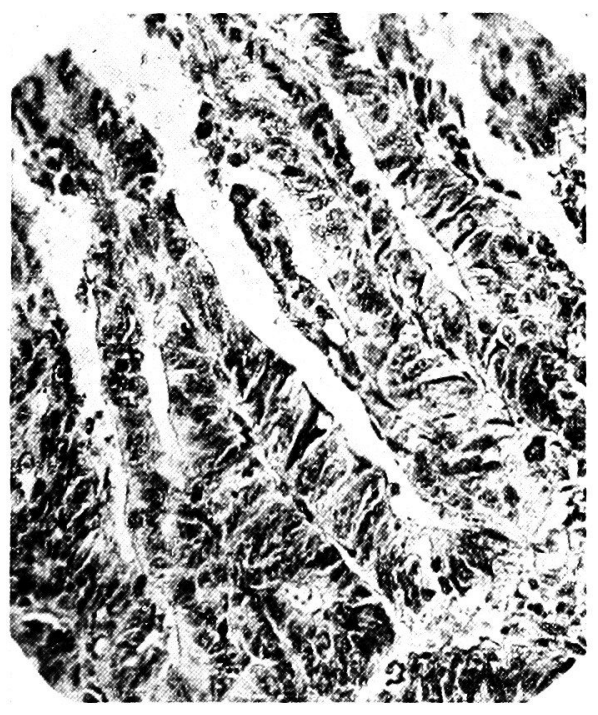



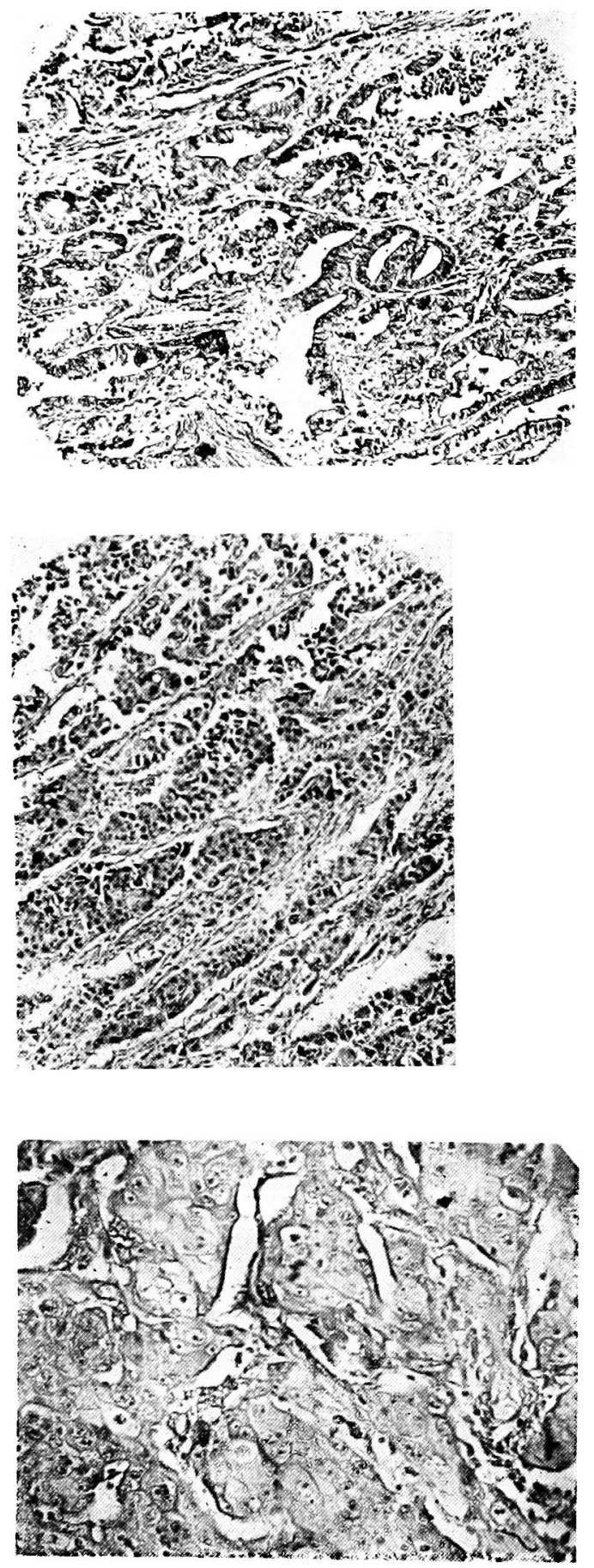

Fig. 7. Carcinoma adenomatosum simplex.

Fig. 8. Carcinoma sclidum alveolare.

Fig. 9. Squamous cell carcinoma. 


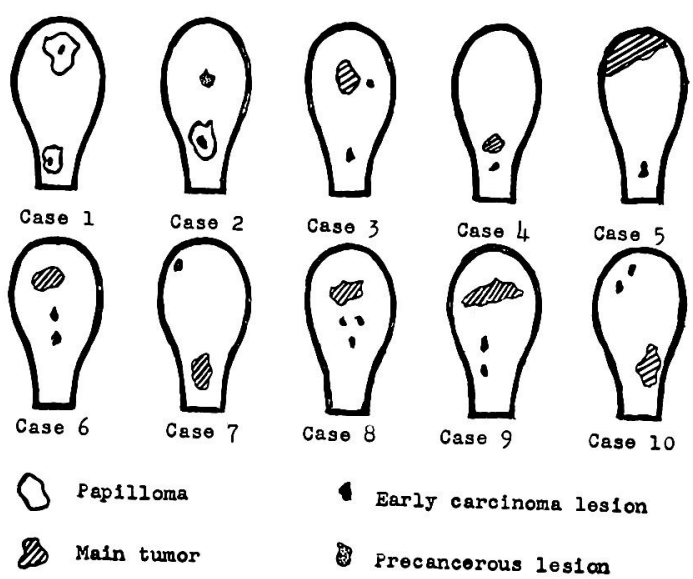

Fig. 10. Diagram showing the site of the early carcinoma or the precancerous lesions.

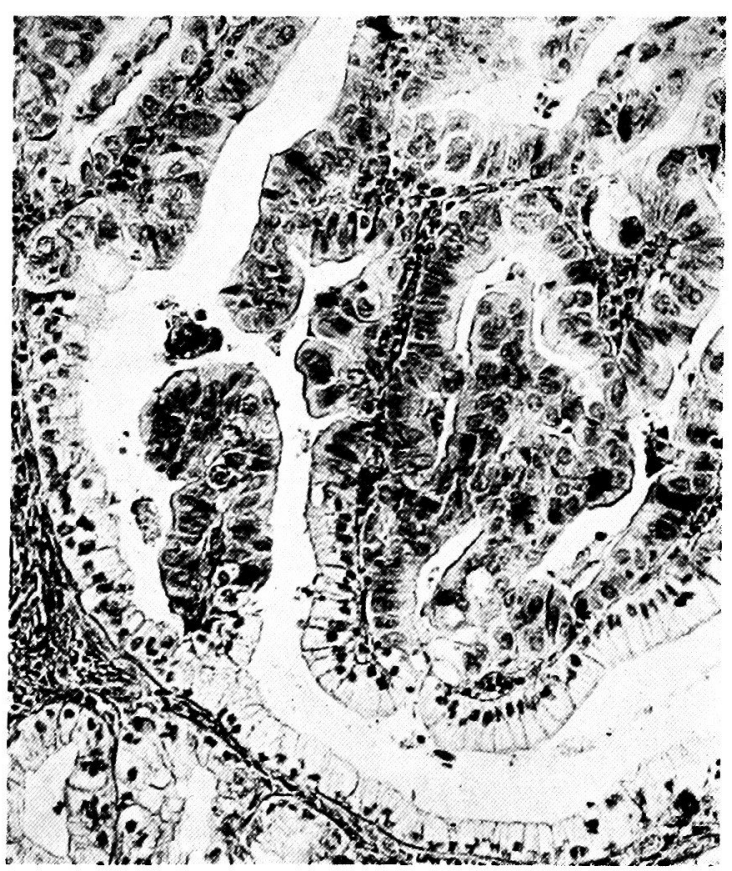

Fig. 11. Carcinoma in situ observed in a papilloma. In part, the cells are not yet malignant, showing the proper structure of papilloma. 

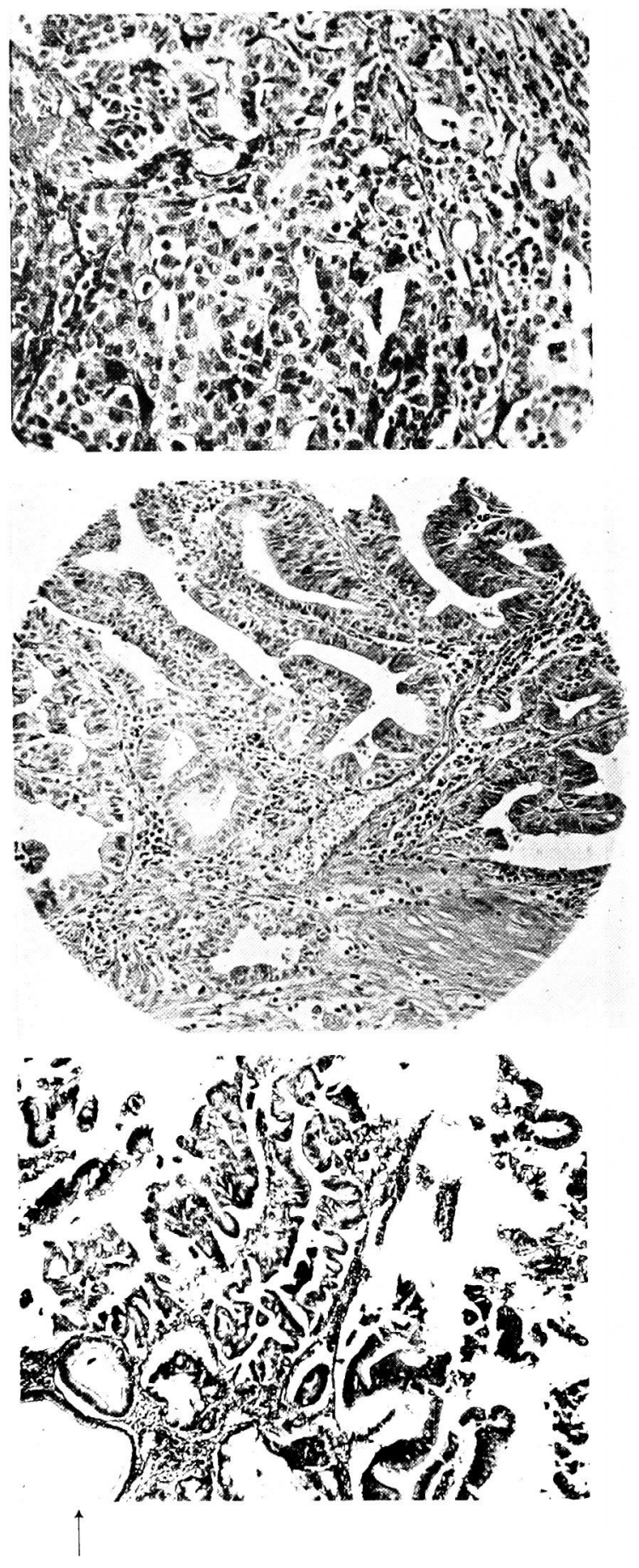

Fig. 12. Early features of the infiltrating growth observed in a part of the carcinoma in situ.

Fig. 13. Early carcinoma lesion observed in the papillarily proliferated epithelium. Incipient features of the infiltrating growth are seen, in part.

Fig. 14. Carcinoma in situ in Case 10.

A part of the cells (shown by an arrow) is high-columnar in form, remaining uninvolved. 